\title{
A NATIONAL SURVEY OF STUDENTS' CONCEPTIONS IN CHEMISTRY IN TAIWAN
}

\author{
Mei-Hung Chiu \\ National Taiwan Normal University \\ Graduate Institute of Science Education \\ mhchiu@ntnu.edu.tw
}

Chemistry is a world filled with interesting phenomenon, appealing experimental activities, and fruitful knowledge for understanding the natural and manufactured worlds. However, it is so complex. Not only do students need to understand the symbols, terminologies, and theories used in learning chemical concepts, but they also need to transform instructional language or materials that teachers use in the chemistry classroom into meaningful representations. Learning chemistry can become challenging work for students of different ages. Although many studies have been conducted in the area of misconceptions (otherwise known as "alternative conceptions" or "student conceptions") in chemistry, few studies exist that systematically collected students' conceptions of their understanding of chemical concepts. Hence, the purpose of this six-year study was to examine students' understanding of a selected set of chemistry concepts (e.g., chemical equilibrium, oxidation/reduction, electrolysis, organic compound, particles, acid/base). Eight professors from universities and colleges were involved in this project and in charge of investigating one (or a few) chemistry concept respectively. This paper presents the progress of this six-year study-a mission-oriented research project-sponsored by the National Science Council in Taiwan. Firstly, the initial two years were to develop two-tier diagnostics tests, which were piloted, analyzed, and revised. They were then submitted to an expert reviewing committee, which selected good-quality test items for use in the national investigation. About 13,500 students - from grades 6 (elementary), 8 and 9 (junior high), and 11 (senior high) —were selected as the target student samples. The results revealed that the students held similar misconceptions as those found in western countries. However, results also showed some atypical misconceptions. Secondly, we examined the potential sources that generated students' misconceptions at the different age levels. The results revealed that sources-such as experiments, reference books, instruction, language, representation of materials in textbooks, or after-school programs-influenced student learning in chemistry. These findings were based upon classroom observation, interviews with teachers and students, and content analysis of written materials. Detailed analyses of the data and educational implications/suggestions are provided.

Key words: misconception, students' conception, chemistry, two-tier test, source

\section{Introduction}

Many studies have shown that students develop their scientific conceptions from many 
Chemical Education International, Vol. 6, No. 1, 2005

www.iupac.org/publications/cei

Paper based on the lecture presented at the 18th ICCE, Istanbul, Turkey, 3-8 August 2004

sources. Those sources have always created inconsistent frameworks or incorrect representation of the scientific concepts. The sources are personal experiences (e.g., observation), gender, peer interaction, media, language, symbolic representation, textbooks, laboratory works, etc. Sometimes, teachers serve as another major source of alternative conceptions (Wandersee, Mintzes, \& Novak, 1994). Research also revealed that students at different ages held similar misconceptions that influenced their understanding of more complex concepts.

Although there are a growing number of researchers devoting their efforts to science learning, Taiwan currently does not have a longitudinal databank of students' performance in science. In other words, Taiwan has yet to apply a systematic method to collecting data for improving our science teaching. Although science educators have developed instructional interventions for conceptual change in learning science, they offer only limited representative information about the difficulties Taiwanese students experience when learning chemistry. Therefore, in order to develop effective learning materials, it was decided to construct a new databank of students' learning status as references for researchers, educators, textbook publishers, and teachers in science education.

\section{Theoretical framework}

Literature on student conceptions about chemistry

Many concepts in chemistry are important for learning and understanding how the world functions in daily life. However, students, either before or after school instruction, cannot develop an appropriate structure of chemistry concepts. For instance, students' conception of matter as a collection of moving particles is rudimentary, and the instruction in this area is not as effective as might be expected (Gabel and Bunce, 1994). Novick and Nussbaum (1978) examined 8th-grade Israeli students' conceptions of the particle nature of matter. They found that "a significant portion of the sample failed to internalize important aspects of the particle model" (p. 278). Students tended to consider the particles as having continuous characteristics. Also, Za'rour (1975) found that 9th- and 11th-grade students considered that the air is composed mostly of oxygen and that heavier objects fall faster than lighter objects.

In the 'acids and bases' part, Ross and Munby (1991) found that $12^{\text {th }}$ graders considered that the acids tasted bitter and hot. Schmidt (1995) also found that even $11^{\text {th }}$ to $13^{\text {th }}$ graders did not have well-developed conceptions about how to differentiate acids from bases. Hwang $(1994,1996)$ found that not only did 5th- and 6th-grade students have difficulty identifying whether a substance was an acid or a base, but their teachers had difficulty as well.

For the concept of chemical equilibrium, Gussarsky and Gorodetsky (1990) found that students had difficulty understanding the dynamic nature of chemical equilibrium. Voska \& Heikkinen (2000) found that even college students did not understand how adding a solid to the solution influences the equilibrium state.

The effect of oxidation and reduction was also a difficult concept for students to conceptualize. Students believed that the oxygen that made the iron rust was from the water and that the rusted iron had the same weight as the original iron (Hesse \& Anderson, 1992). As for the characteristics of matter, Za'rour's study (1975) revealed that matter (e.g., Mg) 
Chemical Education International, Vol. 6, No. 1, 2005

www.iupac.org/publications/cei

Paper based on the lecture presented at the 18th ICCE, Istanbul, Turkey, 3-8 August 2004

decreased its weight after burning. Abraham, Williamson, and Westbook (1994) found that students considered a candle's burning to be a physical change and the process of sugar dissolving to be a chemical change.

The descriptions of student misconceptions described above show that among the many scientific concepts examined within different countries, recursive findings were found at different levels.

\section{Sources of student conceptions}

Although much research has focused on investigating student misconceptions and developing teaching strategies for conceptual change, few researchers have focused on exploring the causes behind the misconceptions. For instance, Herron (1996) argued that languages in chemistry make learning difficult because the meanings of the same words in chemistry are different from the language used in daily life. Also, Oversby (2000) argued that models used in the textbooks only provide explanations of phenomena, and they have their strengths and limitations. Accordingly, the main purpose of this study was to explore the causes of student misconceptions and to find mental models hidden behind student misconceptions of chemistry topics, such as oxidation/reduction, batteries/electrolysis, acids/bases, gas particles, chemical equilibrium, categorization and nature of matters, and material science/organic compounds.

\section{Research questions}

The research questions examined in this study were:

1. What were the types of student conceptions of chemistry?

2. Were there differences in cognitive development of chemistry concepts between junior high and senior high students?

3. What were the sources of student understanding of chemistry?

\section{Methodology}

Research design and participants

As a part of a larger, longitudinal, and mission-based research project, "big ideas" in chemistry were selected to investigate how students performed on those concepts. These big ideas (including oxidation/reduction, batteries/electrolysis, acids/bases, gas particles, chemical equilibrium, categorization and nature of matter, and material science/organic compounds) were chosen based upon the fact that these were key concepts covered in curriculum standards for grades 1-12, found in literatures in chemistry, and among the research experiences of the researchers.

For the first two years of the study, the researchers used concept maps, open-ended questions, and propositional statements to interview students in order to develop two-tier diagnostic tests. After pilot testing, revising, and validating the original tests, more than 200 students were tested and then a panel of experts selected items from each project. Once the test items were selected, they were separated into three booklets so that items in each booklet could be completed within 40-45 minutes (a regular class period for elementary and secondary schools in Taiwan). Each booklet contained 15 test items covering various topics in chemistry. Some items were used as common items across grade levels for the purpose of 
understanding the development of chemistry concepts. A nationwide test was carried out in April 2003. The target students were stratified by regions, school size, etc (similar procedures as were used in Third International Mathematics and Science Study, TIMSS). Test results have provided profiles of student misconceptions and facilitated teacher understandings of students' key science concepts.

The total numbers of students who took the survey were 3,$616 ; 6,990$; and 2,934 for elementary, junior high, and senior high school students respectively.

\section{Results and discussions}

The following sections will cover the distributions of conceptions, comparisons of student outcomes across different grade levels, mental models, and causes of student conceptions. The data reported here is a summary of the study's annual report by the principal investigators of each sub-project in the chemistry group.

\section{A. Distributions of student conceptions of chemical concepts}

The major findings for each sub-project were summarized as shown below.

1. Battery: For elementary school students, Sub-project 1 found that they (Lee, S. J., 2004)

a. could not differentiate the difference between serial and parallel circuits,

b. did not understand how electricity flows in a circuit,

c. considered that electricity could be used up, and

d. considered the two ends of the battery as north and south poles.

2. Oxidation and reduction:

a. For elementary school students, Sub-project 2 found that (Lee, W. D., 2004):

i. they lack knowledge about conditions of combustion (i.e., that wet wood cannot be burnt because of the water in it),

ii. students considered that the candle extinguished because either there was no air or too much carbon dioxide in the beaker, and

iii. they thought the iron lost weight because it rusted.

b. For secondary school students, Sub-project 4 found that (Chou, 2004):

i. close to $50 \%$ of junior high students considered the oxygen to be a combustion gas but that it was not involved in the combustion process (this result was similar to other researchers (i.e., Schollum, 1981; Boujaoude, 1989), and

ii. about $40 \%$ of the students thought that a reduction reaction is when the material is transformed from compound to element. This result is consistent with Garnett and Treagust (1992).

3. Nature of particles:

a. For elementary school students, Sub-project $8(\mathrm{Su}, 2004)$ found that

i. $43.68 \%$ of the students considered that the smallest size of crystal sugar could not be seen by bare eyes but could be seen by a microscope, and

ii. $32.59 \%$ thought that the "smallest" "thing" could been seen is bacteria.

b. For both junior high and senior high school students, Sub-project 3 found that students (Chiu, 2003, 2004; Chiu \& Chou, 2004): 
i. tended to use weight to answer questions about the distribution of particles,

ii. considered the volume of particles themselves to change when the pressure changed, and

iii. considered that the gas particles at a higher pressure pushed the gas particles at a lower pressure without a random distribution characteristic.

4. Acid/Base:

a. For elementary school students, Sub-project 7 revealed that students (Hwang, 2004):

i. did not know how to differentiate the characteristics (acid or base) of a solution, and

ii. considered the solution of sodium bicarbonate and acetic acid to be neutral because it is a neutralization reaction.

b. For secondary school students, Sub-project 3 (Chiu, 2004) revealed that students:

i. considered that the more hydrogen contained within the molecules, the higher the acidity of the compound (similar to Ross \& Munby, 1991), and

ii. considered that the molecule always dissolves in a solution in ionic state.

5. Chemical equilibrium: Sub-project 3 (Chiu, 2004) revealed that

i. secondary school students did not recognize that the shape of sugar changed even at the saturate (equilibrium) state, and

ii. they could hardly understand the dynamic nature of chemical equilibrium. Similar findings were revealed as Gussarsky and Gordetsky (1990).

6. Material science:

a. For junior high school students, Sub-project 5 (Juang, 2004) found that:

i. fewer students answered correctly on items about the characteristics (acid/base) of $\mathrm{C}_{2} \mathrm{H}_{5} \mathrm{OH}$ than the high school students did, but

ii. they had similar misunderstanding as the senior high school students, in that they considered $\mathrm{C}_{2} \mathrm{H}_{5} \mathrm{OH}$ to be a base because of its functional group $(\mathrm{OH})$.

b. For senior high students, we found that:

i. they misunderstood that $\mathrm{NaCl}$ is an organic compound because of its $\mathrm{C}$;

ii. although students understood ethyl alcohol to be an organic compound, the functional group of ethyl alcohol needs a hydroxide ion $\left(\mathrm{OH}^{-}\right)$to make it basic; and

iii. the formula of ethyl alcohol has the most $\mathrm{H}$ atoms, so ethyl alcohol is acidic. Similar result as Chiu's (2004) stated above.

7. Categorization : Sub-project 6 (Hsu, 2004) found that

a. $10.84 \%$ of elementary school students and $30.35 \%$ of eighth graders were influenced by the Chinese name given to the compound. For instance, $\mathrm{Hg}$ is 
Chemical Education International, Vol. 6, No. 1, 2005

www.iupac.org/publications/cei

Paper based on the lecture presented at the 18th ICCE, Istanbul, Turkey, 3-8 August 2004

called 抔銀 (in Chinese, the first character 扰 meaning water and the second character 銀 meaning silver respectively). In particular, the left part of the second character ( 金) always implying a kind of metal.

b. Similarly, diamond is called 銑石 in Chinese, the first character also has the same character of metal ( 金) on the left side, therefore $24.89 \%$ of elementary school students considered the diamond is a metal while $23.20 \%$ of the eighth graders did so.

\section{B. Comparisons between junior high and senior high school students on the common test items}

As stated earlier, we have some same or similar test items in the booklets for both junior and senior high school students. We found that those test items tested across grade levels showed similar patterns for the junior and senior high school students. This means that students construct their cognitive structure of the concepts via a gradual development process. Some concepts were not developed well or completely while students were young. Therefore, their structure of knowledge revealed gaps, incompleteness, or flaws.

\section{Sources of student conceptions}

The last part of the analyses is about the causes of student conceptions. To explore what causes students difficulty in learning chemistry, we interviewed the students and teachers, analyzed the textbooks, and observed classroom teaching. Through these means, we found that students, regardless of grade level, showed various causes for their conceptions of chemistry: daily life experience, textbooks, media, language, school instruction. The most impressive finding was the Chinese characters that, on the one hand, served as a facilitator to help students understand the nature of chemistry (such as acid rain), and on the other hand, created a detrimental effect on students' conceptualization. For instance, the students mistook the character 酸 in naming carbon hydrate in Chinese as acid instead of considering its basicity in water. Sometimes, they see $\mathrm{H}$ in a chemical formula; they consider it is an acid. . Other examples were discussed earlier. So, the Chinese character or the symbols can be seen as a double-edged sword in learning chemistry.

\section{Conclusion and implication}

There were three major perspectives from which to investigate our students' conceptions of chemistry. First, from the analysis of types of student conceptions, we found an incomplete, under-developed, flawed structure of various levels of students' knowledge about chemistry. Second, although the progression of students' cognitive development was slow, the nature of their conceptions was sometimes similar. These findings might explain why we saw similar high or low performance on the common test items for different grades of students. Third, the sources of generated student conceptions were various. Although we could hardly pinpoint all the possible sources of misconceptions, we do know that students come to our classrooms with various backgrounds that might help or hinder their correct 
Chemical Education International, Vol. 6, No. 1, 2005

www.iupac.org/publications/cei

Paper based on the lecture presented at the 18th ICCE, Istanbul, Turkey, 3-8 August 2004

understanding of scientific concepts.

After working on this project for four years, we consider the important implications for science education to be (1) the need for a databank of student conceptions of chemistry, with a comparison of findings from other countries with different cultural backgrounds (i.e., universal vs. local findings); (2) the need to explore social, cultural, and educational effects; and (3) the development of tools for meaningful learning. The last recommendation is the main goal for our fifth and sixth years' projects.

\section{Acknowledgment}

The author would like to thank the National Science Council for support of this project (grant \#NSC 91-2522-S-003-022-; 91-2522-S-003-020-; 92-2511-S-003-060; 92-2522-S-003-010). Also, the principle investigators of the chemistry part of NSLS projects: W. D. Lee, S. J. Lee, C. Y. Chou, L. R. Hsu, C. S. Juang, W. C. Hwang, and Y. R. Su. In addition, colleagues for the entire project, C. G. Guo, Y. W. Gou, Y. Y. Lu, I. Huang, C. Y. Lin, H. P. Chang, and C. C. Chang. Finally, special thanks to C. C. Chou and J. C. Liang for their thoughtful suggestions, data collection and analysis.

\section{References}

Abraham, M. R., Williamson, V. M., \& Westbrook, S. L. (1994). A cross-age study of the understanding of five chemistry concepts. Journal of Research in Science Teaching, 31(2), 147-165.

Chou, C. C. \& Chiu, M. H. (2004). A two-tier multiple choice diagnostic instrument on the molecular representations of chemistry: Comparisons of performance between junior high and senior high school students in Taiwan, Paper presented at $18^{\text {th }}$ Iternational Conference on Chemical Education, August 3-8, Istanbul, Turkey.

Chiu, M. H. (2004). An investigation of exploring mental models and causes of secondary school students' misconceptions in acids-bases, particle theory, and chemical equilibrium. Annual report to National Science Council in Taiwan (in Chinese).

Chou, C. Y. (2004). The misconceptions and causes of secondary school students on oxidation and reduction. Annual report to National Science Council in Taiwan (in Chinese).

Gabel, D. L. \& Bunce, D. M. (1994). Research on problem solving: Chemistry. In D. Gabel (Ed.), Handbook of Research on Science Teaching and Learning (pp. 301-316), New York: Macmillan Publishing Company.

Garnett, P. J. \& Treagust, D. F. (1992). Conceptual difficulties experienced by senior high school students of electrochemistry: Electrochemical (Galvanic) and electrolytic cells, Journal of Research in Science Teaching, 29, 10, 1079-1099.

Gussarsky, E. \& Gorodetsky, M. (1990). On the concept "chemical equilibrium": The associative framework. Journal of Research in Science Teaching, 27, 197-204.

Herron, J. D. (1996). The Chemistry Classroom: Formulas for Successful Teaching. Washington, DC: American Chemical Society.

Hesse, J. \& Anderson, C. (1992). Students' conceptions of chemical change. Journal of Research in Science Teaching, 29, 3, 277-299.

Hsu, L. R. (2004). A study of conceptual formation on classification of chemical property. Annual report to National Science Council in Taiwan (in Chinese). 
Hwang, W. C. (2004). The types and causes of misconceptions of elementary students on acids-bases. Annual report to the National Science Council in Taiwan (in Chinese).

Juang, C. S. (2004). The misconceptions of secondary school students on material science and organic compounds. Annual report to National Science Council in Taiwan (in Chinese).

Lee, S.J. (2004). A study of cognitive development and teaching strategies of batteries and electrolysis for the elementary school students. Annual report to the National Science Council in Taiwan (in Chinese).

Lee, W.D. (2004) A study on causes of elementary school students' misconceptions in oxidation-reduction. Annual report to the National Science Council in Taiwan (in Chinese).

Novick, S., \& Nussbaum, J. (1978). Junior high school pupils' understanding of the particulate nature of matter: an interview study. Science Education, 62, 3, 273-281.

Oversby, J. (2000). Models in explanations of chemistry: The case of acidity. In J. K. Gilbert \& C. J. Boulter (Eds.), Developing Models in Science Education. Dordrecht/Boston/London: Kluwer Academic.

Ross, B. \& Munby, H. (1991). Concept mapping and misconceptions: a study of high school students' understandings of acids and bases. International Journal of Science Education, $13,11-23$.

Schmidt, H-J. (1995). Applying the concept of conjugation to the Bronsted theory of acid-base reactions by senior high school students from Germany. International Journal of Science Education, 17(6), 733-742.

Voska, K. W. \& Heikkinen, H. W. (2000). Identification and analysis of student conceptions used to solve chemical equilibrium problems. Journal of Research in Science Teaching, 37(2), 160-176.

Wandersee, J. H., Mintzes, J. J., \& Novak, J. D. (1994). Research on alternative conceptions in science. In D. L. Gabel (Ed.), Handbook of Research on Science Teaching and Learning. New York: Macmillan.

Za'rour, G. I. (1975). Science misconceptions among certain groups of students in Lebanon. Journal of Research in Science Teaching, 12(4), 385-391. 